\title{
(Cr/TiAlCrN/TiAlN/AlSiN/AlSiO) Multi Layer Solar Selective Coatings for Concentrated Solar Power Plant
}

\author{
A.Sandeep, Sivakumar Ellappan
}

\begin{abstract}
A multi layer solar selective coating $\mathrm{Cr} / \mathrm{TiAlCrN} / \mathrm{TiAlN} / \mathrm{AlSiN} / \mathrm{AlSiO}$ gives the good absorption $(\alpha=$ $0.95)$ and low emission $(G=0.08)$ over the $S S 316$ tube for solar thermal applications. In this multi layer solar selective coating each layer has unique properties that mostly depend upon the each layer thickness. Individual layer thickness has been optimized to get high absorbance $(\alpha=0.95)$ and low emission $(\epsilon=$ 0.08). metal nitride multilayer films display a unique combination of exceptional properties with respect to optical absorption, thermal emission, corrosion resistance, adhesion between coating and surface and thermal stability at high temperatures. The sequence of the Cr/TiAlCrN/TiAlN/AlSiN/AlSiO coating layers was selected based on their relative thickness, which was optimized to get good solar selectivity $(\alpha / \epsilon)$. The multilayer solar selective coating was characterized by using Raman spectrometer, Ultra violet-VisibleNIR spectrophotometer, Scanning electron microscope (SEM), Transmission electron microscopy (TEM) etc. Scratch test was used to find the coating adhesion strength and corrosion tests were also done for these absorber coatings.
\end{abstract}

Key words: multi layer, high absorption, solar selective coating

\section{INTRODUCTION}

Invention of Solar Cells is a very successful attempt to generate electric power from solar energy. Solar cells are categorized as photovoltaic and solar thermal collector. In the former category, solar energy is directly converted into electricity. In the latter, solar energy is converted into thermal energy and then to electrical energy. Theoretical and experimental progress has been seen in both the types of solar cells. The present work deals with exploring solar thermal.

\section{Metal nitride multilayer absorbers}

In recent years, solar energy utilization has increased. It is an eco free and non-polluting idea that converts the everlasting solar radiation into thermal energy/electrical energy used to fulfil the increasing demand of the energy requirements [1]. Parabolic trough power plants are an assembly of large fields of parabolic trough collectors, steam generating systems, steam turbines/ generator cycles, thermal storage systems and fossil fired back up systems [2]. It can be seen that the efficiency of a solar cell is majorly dependent on the type of the absorber coatings being used. [3], an ideal selective coating is one, which satisfies the following requirements [4]: High absorption $(\alpha)$ over solar

\footnotetext{
Revised Manuscript Received on September 10, 2019.

A.Sandeep, M.Tech Student, Deportment of Mechanical Engineering, MLR Institute of Technology, Hyderabad, Telangana, India

(E-mail: sandeepambati76@gmail.com)

Sivakumar Ellappan, Deportment of Mechanical Engineering, MLR Institute of Technology, Hyderabad, Telangana, India

(E-mail: sivaraani1977@gmail.com)
}

selective region (0.3-2.5 $\mu \mathrm{m})$, low emissivity $(\epsilon)$ in the I.R region $(2.5-50 \mu \mathrm{m})$ and sharp spectral transition. Being polymer based coatings they low thermal conductivity [5]. In the recent years, among all the above absorbers, thin films (can be mono or multilayer) with their excellent tuneable optical properties are widely used as solar selective coatings $[6,7]$. In actual practice, so far there were no reported ideal selective coatings. There were many attempts only to maximize ' $\alpha$ ' and minimize ' $C$ ' to achieve a high selectivity $(\alpha / \mathcal{E})[8,9]$. The ideal solar thermal reflectance spectra is shown in fig. 1 [10]

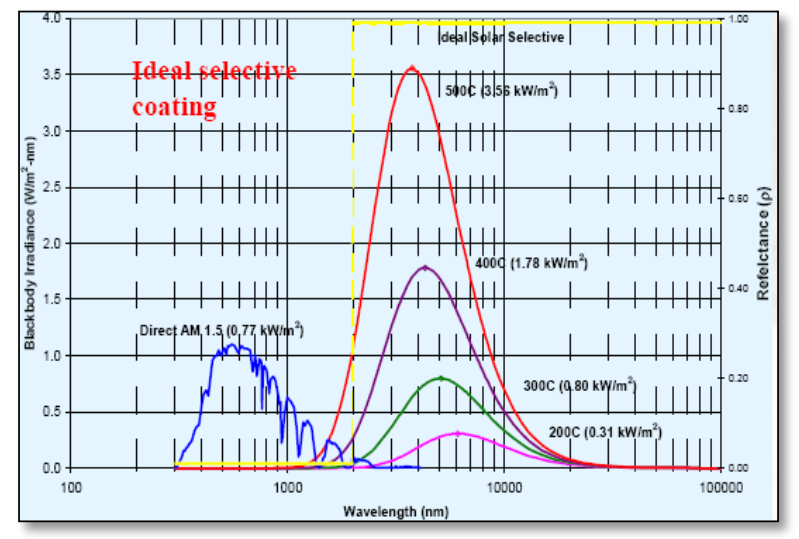

Figure 1. Ideal solar thermal absorber reflectance spectra

Most of these coatings suffers from poor oxidation resistance $\left(>135^{\circ} \mathrm{C}\right)[11]$ and contains water inclusions resulting in lower life time due to continuous exposure to sun light. In addition to the above factors the advanced receiver technology demands coatings that are stable up to $600^{\circ} \mathrm{C}$. From literature, these high end applications can be easily addressed through the use of PVD developed solar absorber coatings. In general, so far, most of the reported absorber materials are metal oxides [12-19] and there are very few nitrides [8-10]. Barshilia et al. [20, 21] recently reported $\mathrm{Ag}-\mathrm{Al}_{2} \mathrm{O}_{3}$ solar selective coatings with absorbance and emission of $0.93,0.04-0.05$ respectively at $82^{\circ} \mathrm{C}$ in the IR region. The same group has also reported TiAlN/TiAlON $/ \mathrm{Si}_{3} \mathrm{~N}_{4}$ absorber grown using magnetron sputtering. These absorbers are reported to be air stable up to $600^{\circ} \mathrm{C}$ with absorbance of 0.95 and emission 0.07 . Y. Yin et al. [6] in his studies related to $\mathrm{Cr}$ based absorbers reported $\mathrm{Cr}-\mathrm{Cr}_{2} \mathrm{O}_{3}$ cermet solar selective coatings. For these coatings, an absorbance of 0.92- 0.96 and thermal emittance $0.05-$ 0.08 was observed with thermally stability up to $300-400^{\circ} \mathrm{C}$. 
In the case of nitride absorber coatings, Godinho et al. [7] developed TiAlN coatings that are thermally stable up to $600^{\circ} \mathrm{C}$.

\section{EXPERIMENTAL PROCEDURE}

\section{Principle}

In this process a material is vaporized by means of a high temperature arc and made to condense on the desired object leading to a thin film formation. The source material is taken as cathode. A metallic striker is then used to strike cathode. An arc is then established between them when striker hits the cathode. This arc can be distributed on to every spot of cathode by magnetic fields, which is induced by a combination of permanent magnets and electric coils. These are called cathode spots and are of typical dimensions in microns. The temperature in this region goes to as high as $15000^{\circ} \mathrm{C}$. The metal in those spots get evaporated into chamber. The cathode spot is only active for a short period of time, and then it self-extinguishes and re-ignites in a new area close to the previous one due to magnetic fields. The cathodes are kept rotating to make the evaporation uniform from the cathode. The substrate which is anode in this process attracts the emitted vapor particle in chamber. Often substrate is etched before deposition for good adhesion between them. This can be performed with Ar gas or metal ions. For argon gas etching, Ar gas is introduced into the chamber with high bias due to that Ar gas gets ionized for good surface finish of the substrates. These Ar ions sputter on the surface and remove top most layer of substrate, which are generally oxide films and other impurities. Thus, a mirror finished layer is obtained after Ar etching. After that metal ion etching is carried out. During metal ion etching, the ionized particles of target are directed towards substrate with greater velocity under vacuum where these metal ions diffuse into substrate. The given below fig. 1 shows the Cathodic arc physical vapor deposition equipment

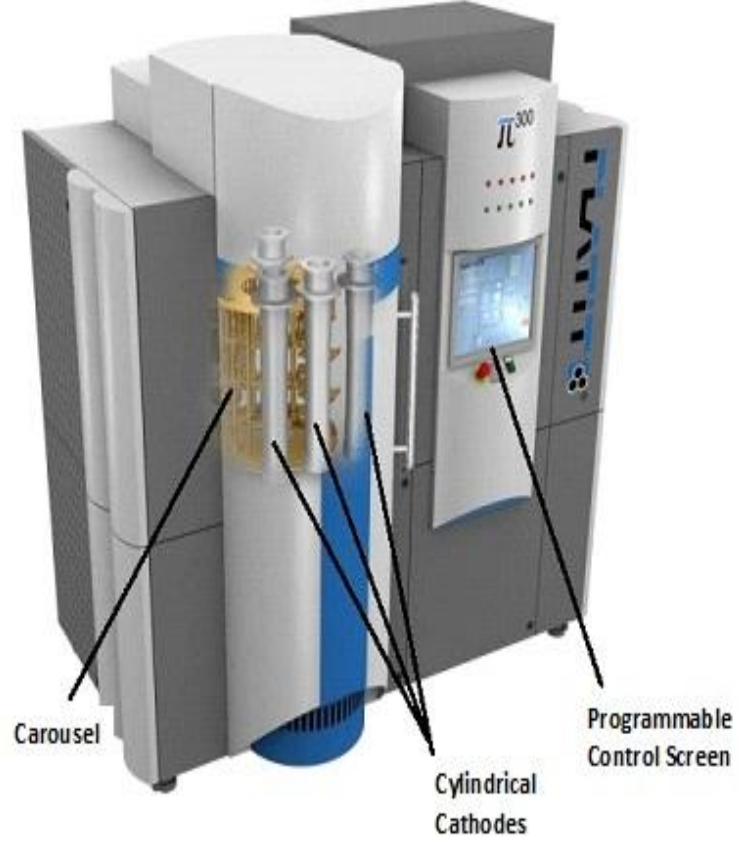

Figure 2: Cathodic Arc thin film deposition facility available at ARCI (PLATIT $\pi^{300}$ )

\section{Pre-Treatment of samples}

Substrate surface plays a major role in determining the properties of coating such as adhesion strength, hardness, corrosion resistance and durability etc. So controlling surface contamination is an important factor to obtain effective coatings. Cleaning of the substrate surface implies degreasing, removal of dust or unwanted particles and organic substances, presence of which degrade the quality of the product. Often cleaning process involves a combination of cleaning processes to obtain the best result. In the present study TERMOVIDE cleaning unit is adopted. In the equipment, cleaning and conditioning is carried through a series of processes.

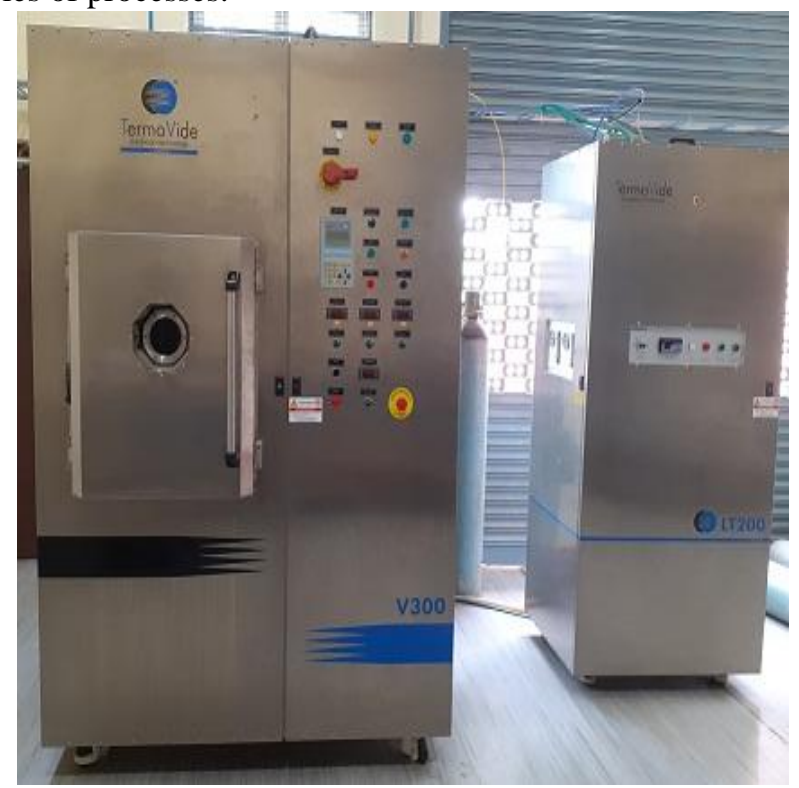

Fig 3: Cleaning unit (Thermovide V300)

Pre-cleaning of substrates is done for 40 minutes in the Thermovide V300 Pre-Cleaning Unit (shown in fig 3), maintained at a temperature of $60-70^{\circ} \mathrm{C}$. Firstly, the substrates are cleansed with an alkaline soap solution under the action of ultrasonic waves for five minutes, followed by rinsing in deionised water for ten minutes and dried for 25 min in hot air. Then the samples are taken out and loaded in the deposition chamber, and is evacuated to a base pressure of $1 \times 10^{-5} \mathrm{~m}$ bar and heated to a temperature of $400{ }^{\circ} \mathrm{C}$. Then the samples are subjected to Argon etching followed by metal ion etching.

\section{Scratch Testing (Evaluation of Critical Load)}

Scratch tester is being used to study adhesion properties of coatings from many years. Adhesion strength is to be known to estimate the performance of the material.

\section{Principle}

A vertical load is applied on to a coated substrate and with this load indenter is moved to some length (nearly $4 \mathrm{~mm}$ ) in this process the load being increased progressively until the complete coating shear off (LC2) this point is called delamination. The given below fig. 4 shows the scratch tester 

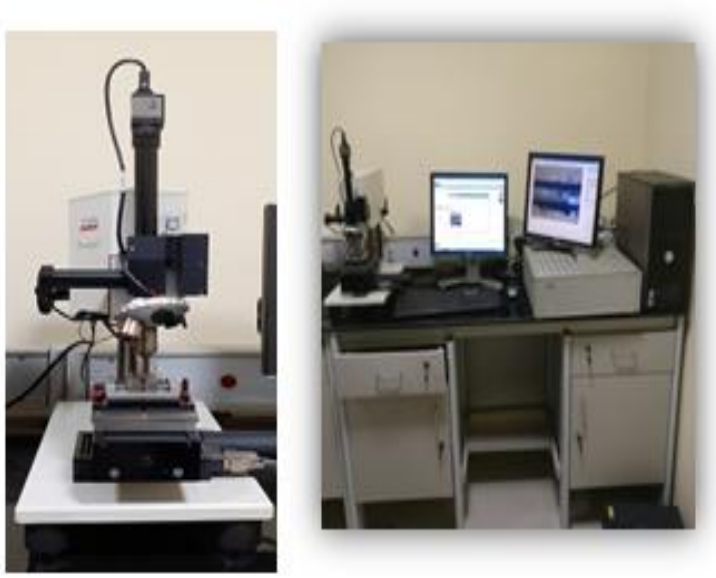

Fig 4: Scratch tester (CSM model Revetest)

\section{Nano indentation}

Nano indentation equipment (CSM model NHTX) was adopted in this study to investigate the mechanical properties of thin films. This test provides the information of the elastic modulus and hardness. Since the substrate effect is excluded the results are precise in this method.

\section{Principle}

The principle of Nanoindentation lies in bringing a very small tip of the indenter to the material surface with forces in between $1 \mu \mathrm{N}$ to $100 \mathrm{mN}$ producing an imprint. Since the hardness is the measure of resistance to indentation coating hardness can be obtained. Hardness is measure of projected area of the indent. The Nano indentation shown in fig.5
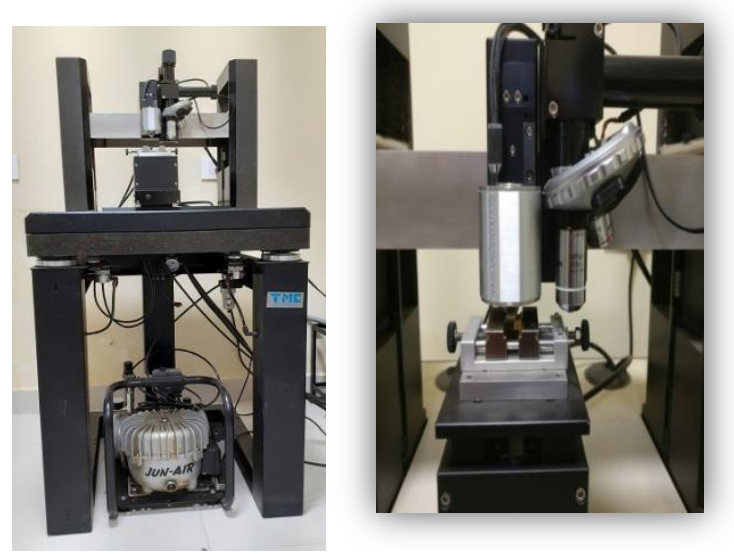

Fig 5: Nano indentation equipment (CSM model NHTX)

\section{RESULTS AND DISCUSSION Cr/TiAICrN/TiAIN/AISiN SOLAR SELECTIVE COATING}

\section{Identification of absorber material}

In this part of the work, identification of the best absorber material that could be formed using available cathodes $(\mathrm{Ti}$, AlTi, AlSi, Cr). It was done using constant deposition parameters, i.e. Nitrogen partial pressure while coating, individual layer thickness, substrate temperature, substrate bias. The optical absorbance (300-2500 nm) and thermal emission $(2.5-50 \mu \mathrm{m})$ were measured (Table 1) from these material combination. Reflectance spectra of different possible nitride films are shown in Fig. 6

\begin{tabular}{|llll|}
\hline Substrate/metal & $\alpha(\%)$ & Coating & $\alpha(\%)$ \\
\hline $\mathrm{SS}$ & 22 & TiN & 27 \\
\hline $\mathrm{SiC}$ & 39 & CrN & 68 \\
\hline $\mathrm{Ti}$ & 83 & AlSiN & 52 \\
\hline $\mathrm{Cr}$ & 44 & TiAlN & 69 \\
\hline
\end{tabular}

Table 1: Absorption values of different substrates, metals and metal nitride films

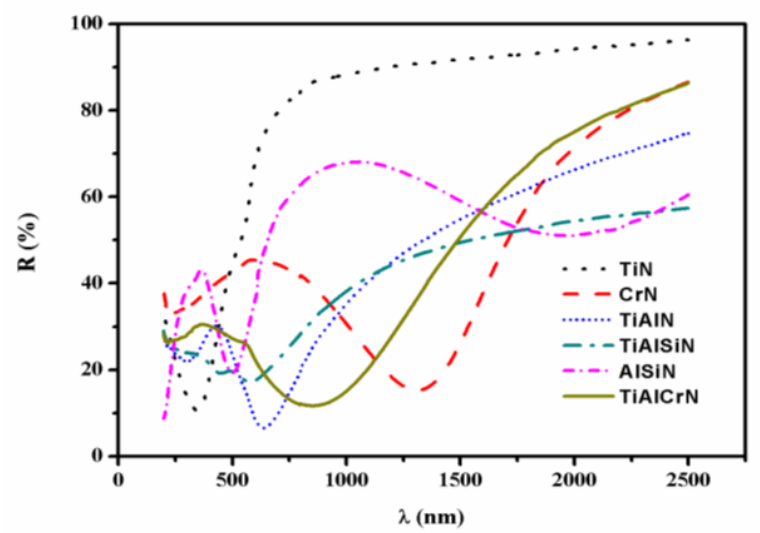

Figure 6: Reflectance spectra of different possible material combinations

From these results it was observed that, the films with maximum $\mathrm{Cr}$ content have maximum absorbance followed by those with TiAlN (Al rich Al-60\%). Hence, the solar absorber coating was selected such that it should contain the $\mathrm{Cr}$ rich nitride and TiAlN layers as absorbers. In addition to absorber layer selection, antireflective coating selection also has been done by growing different nitrides on the identified absorber coating. Out of all possible nitrides, AlSiN coating has shown better results. Hence in all further studies AlSiN has been taken as antireflective coating. After identification of proper absorber materials they were stacked in different ways to identify the best combination. The number of layers required is also optimized. From the results, the multilayer with three layer structure has shown best optical properties. The schematic of the multilayer structure is shown in Fig. 7

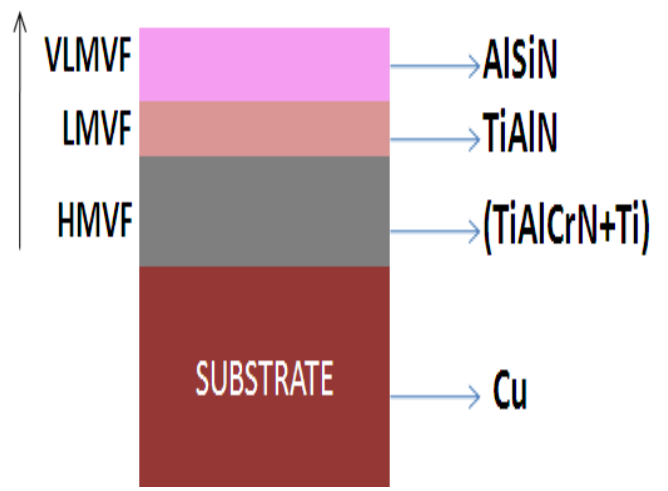

Figure 7: Schematic of optimized multilayer solar absorber 
Where, high metal volume fraction (HMVF) and low metal volume fraction (LMVF) gives the good absorption and anti-reflectance for solar thin film coatings.

\section{Optimization of multilayer combination}

Using of different possible absorber materials best multilayer sequence with highest absorbance in the solar spectral region is identified. The reflectance spectra of multilayer coating with different sequence of constituent thin films are shown in Fig. 8 from the results, the combination: $\mathrm{Cr} / \mathrm{TiAlCrN}$ )/ TiAlN/ AlSiN have highest absorbance and low emission (absorption 0.95 and emission $0.08)$.

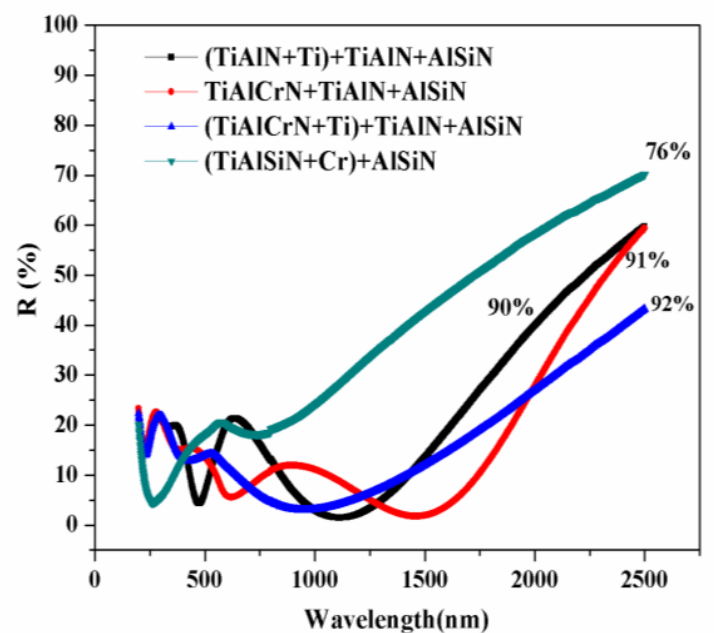

Figure 8: Reflectance spectra of coating consisting of different multilayer combinations.

\section{Substrate effect}

Since there could be an effect of substrate on absorption properties, the effect of substrate material on the optical properties of optimized film was also studied. The complete results pertaining to substrate effects are summarised in Fig. 9 Due to its inherent property, coatings on Silica carbide (SiC) have shown highest absorption when compared to copper $(\mathrm{Cu})$ and Stainless steel (SS). However, it was observed that $\mathrm{SiC}$ never withstand the mechanical strength as compared with $\mathrm{Cu}$ and SS-316 substrates and SS-316 and $\mathrm{Cu}$ substrates exhibit almost equal absorption but different thermal emission.

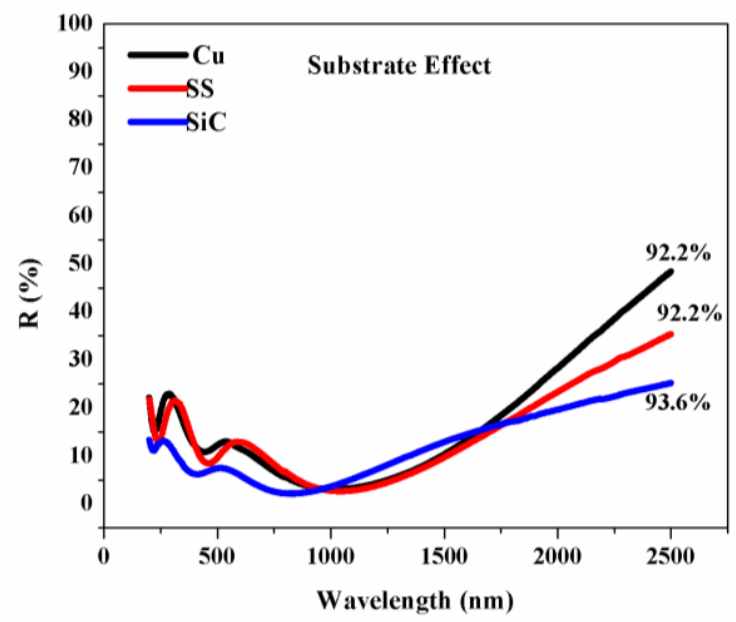

Figure 9: Substrate effect on solar absorbance of multilayer thin films.

\section{Optimization of TiAlCrN layer}

After identification of multilayer combination each layer has been optimized with respect to different metal volume fraction. This was achieved by varying the cathode currents and nitrogen partial pressure. The effect of thickness is also optimized. The optical properties were found to depend largely on thickness of the film. The results clearly indicate the requirement of low operating nitrogen partial pressure for enhancement of absorbance. The observed, optimized metal compositions are: $\mathrm{Ti}-14 \%, \mathrm{Cr}-10 \% \mathrm{Al}-19 \%$ and nitrogen partial pressure $5 \times 10^{-3}$ mbar with $90 \mathrm{~nm}$ thickness. With increase of $\mathrm{Ti}$ concentration the optical absorbance decreases exponentially (Fig. 10 and 11). Whereas with increase in $\mathrm{Cr}$ concentration an exponential increase in absorption is noticed (Fig. 12 and 13). The results pertaining to nitrogen partial pressure, thickness optimization were shown in Fig. 14, 15 and 16 respectively.

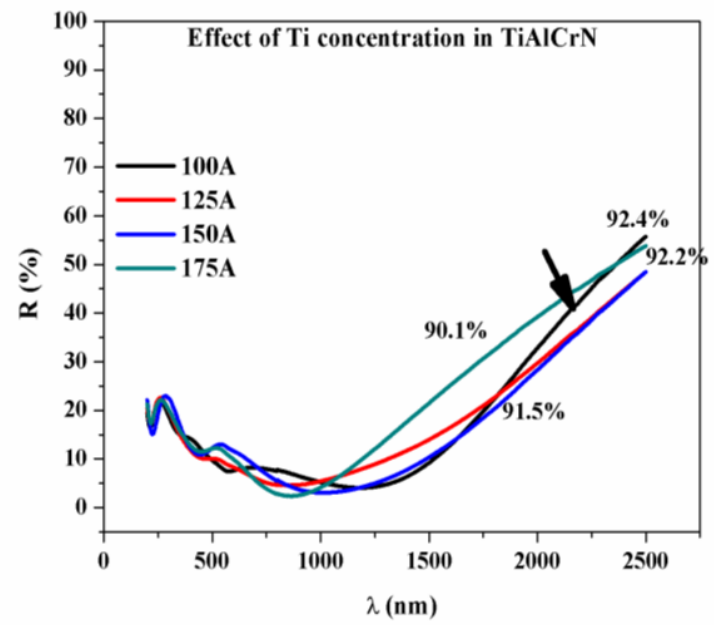

Figure 10: Reflectance spectra with $\mathrm{Ti}$ concentration variation.

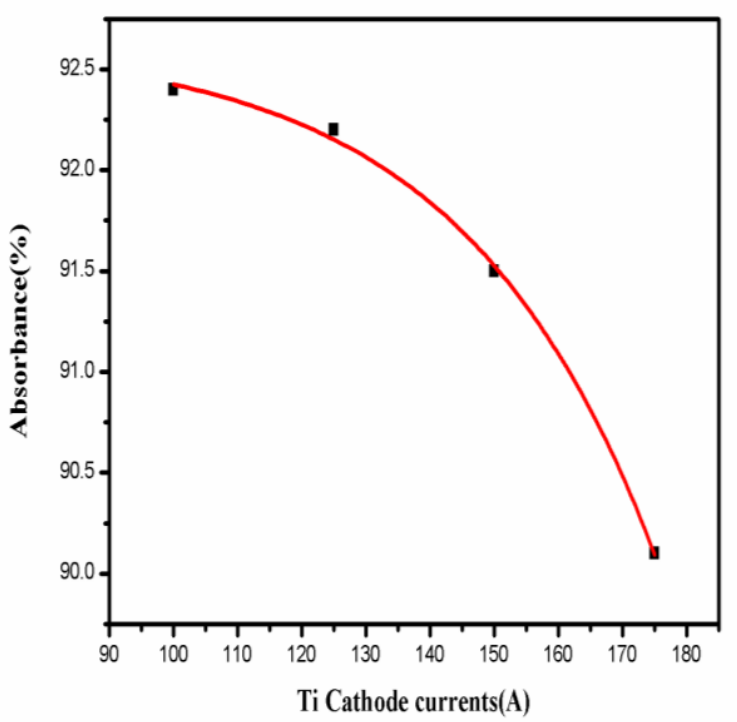

Figure 11: Ti cathode current VS absorption. 


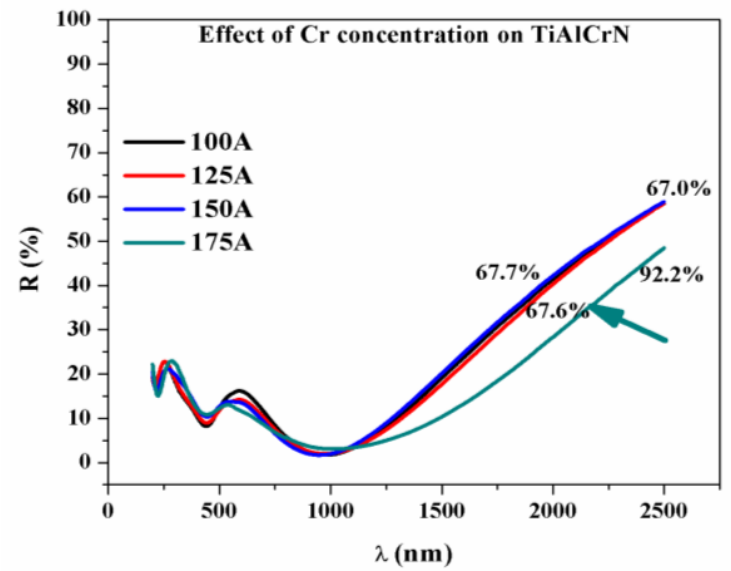

Figure 12: Reflectance spectra with $\mathrm{Cr}$ concentration variation

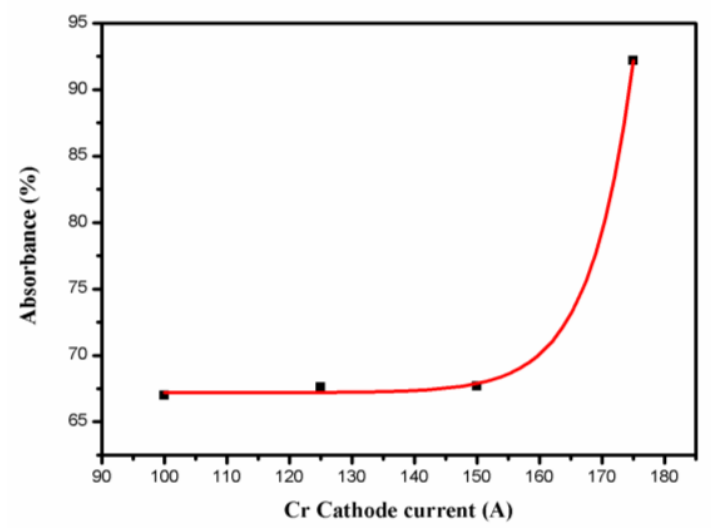

Figure 13: Cr cathode current VS absorption.

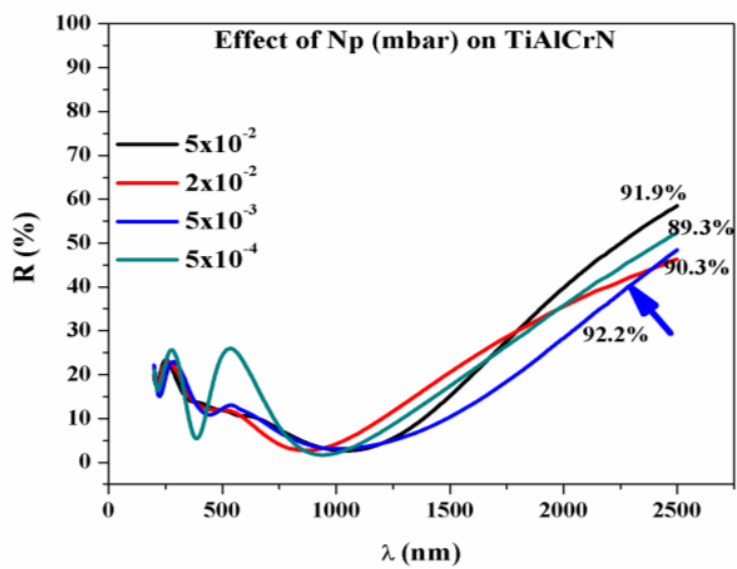

Figure 14: Reflectance spectra with $\mathrm{N}_{\mathrm{p}}$ variation.

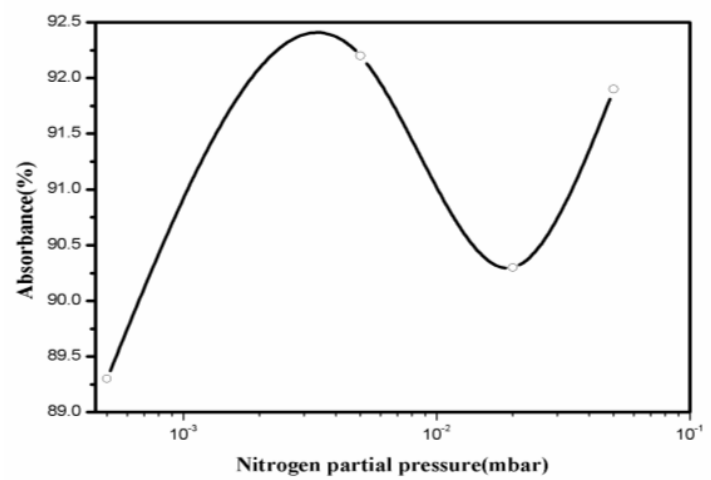

Figure 15: Nitrogen partial pressure $\left(\mathbf{N}_{\mathrm{p}}\right)$ VS absorption.

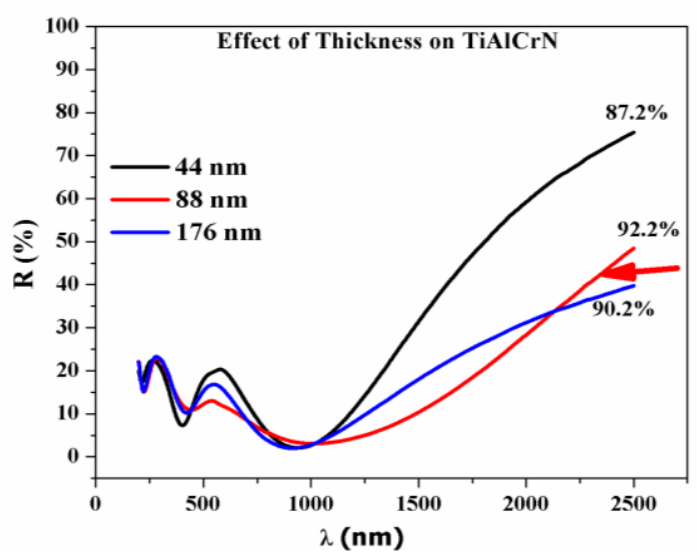

Figure 16: Reflectance spectra with thickness variation.

\section{Optimization of TiAlN layer}

Similar to the optimization of previous thin film, this layer was also optimized for $\mathrm{Ti}, \mathrm{Cr}$ concentrations, reactive nitrogen partial pressure and thickness. The reflectance spectra's were shown in Fig. 17, 18, 19 and 20 respectively.

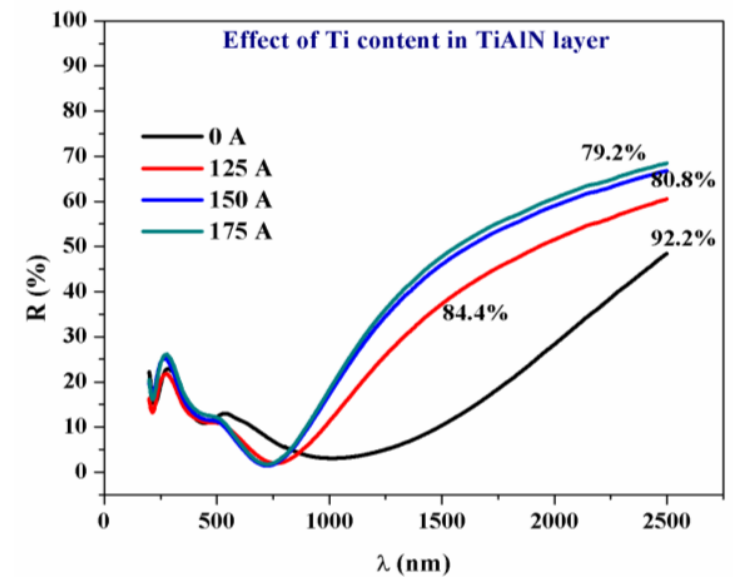

Figure 17: Reflectance spectra with Ti concentration variation.

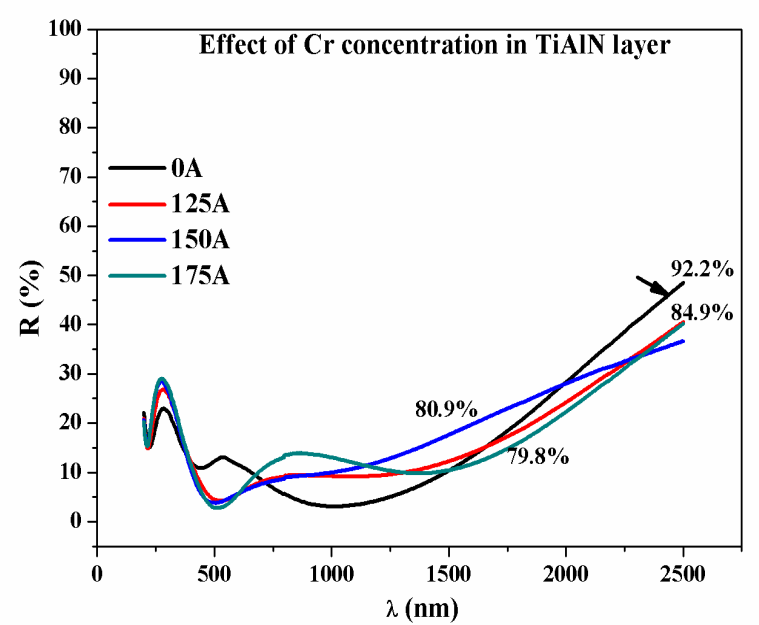

Figure 18: Reflectance spectra with $\mathrm{Cr}$ concentration variation.

Published By: 
In this layer with extra addition of either $\mathrm{Ti}$ or $\mathrm{Cr}$ results in degradation of optical properties. This could be due to enhanced metallic nature which should not exceed previous layer (the layer structure should be such that the metallic metallic content should decrease as one approaches outer surface of the coating). Godinho et al. reported that $\mathrm{Al}$ concentration in TiAlN layer affects on reflectance and thermal emittance [3]. The optimized parameters in this case are: $275 \mathrm{~A}$ TiAl cathode current, $2 \times 10^{-2}$ mbar nitrogen partial pressure and $45 \mathrm{~nm}$ layer thickness.

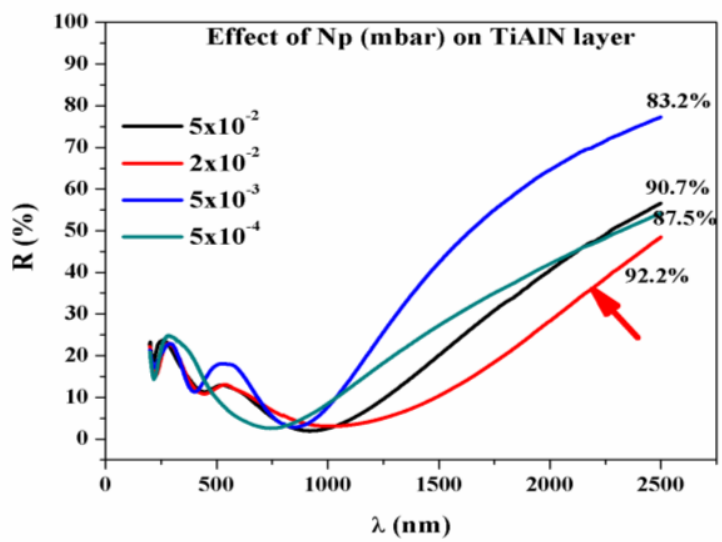

Figure 19: Reflectance spectra with $N_{p}$ variation.

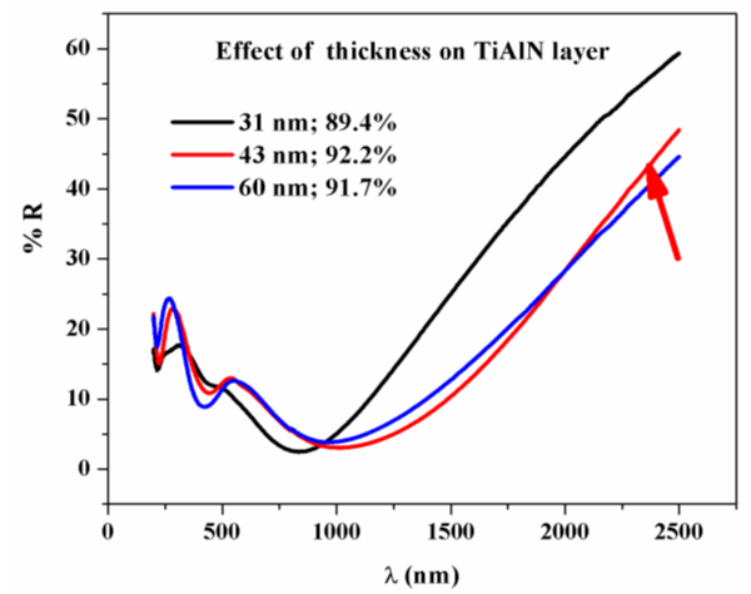

Figure 20: Reflectance spectra with thickness variation.

Optimization of AlSiN layer

This layer is the outermost layer and will be acting like antireflective coating. Here, optimization has been done by varying nitrogen partial pressures and thickness but not metal concentration (since it should not contain any metal content which enhances reflection). The optimized nitrogen partial pressure and thickness are $2 \times 10^{-2}$ mbar and $35 \mathrm{~nm}$ respectively. The reflectance spectra with nitrogen partial pressure and thickness variations were shown in Fig. 21 and 22 respectively.

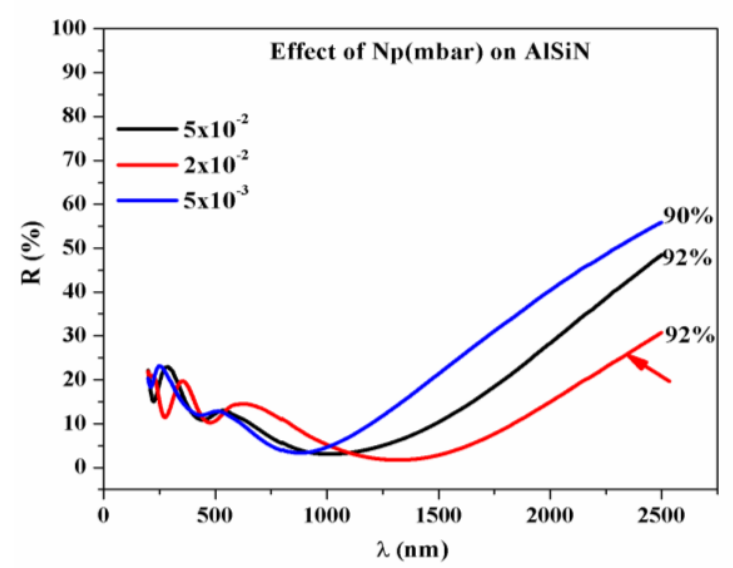

Figure 21: Reflectance spectra with $\mathbf{N}_{\mathrm{p}}$.

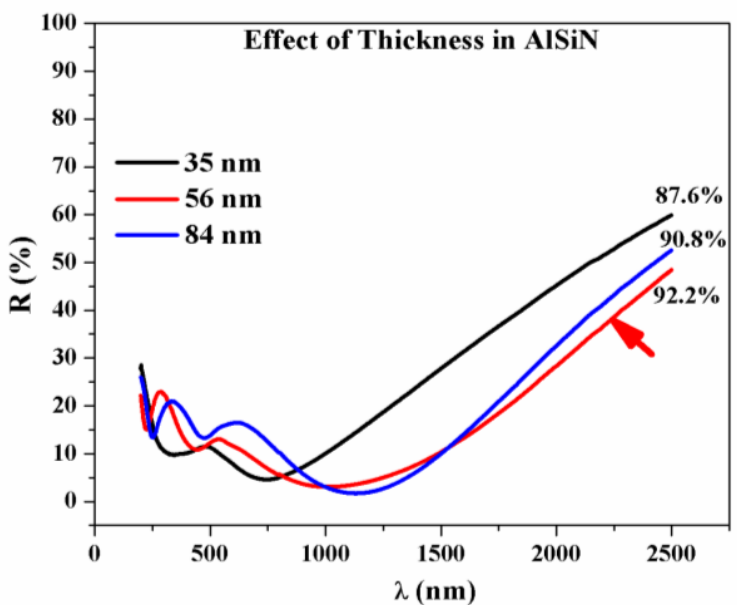

Figure 22: Reflectance spectra with thickness.

Over all optimized solar absorber multi layer structure

The multilayer with above optimized parameters of each layer resulted in $92.3 \%$ absorption and $14 \%$ emission. In the process further optimization with respect to emission, the overall coating thickness reduction became essential. Hence, an optimization of overall film thickness found to result in best properties at $126 \mathrm{~nm}$ with absorption $91.3 \%$ and emission $7 \%$ (Fig. 23)

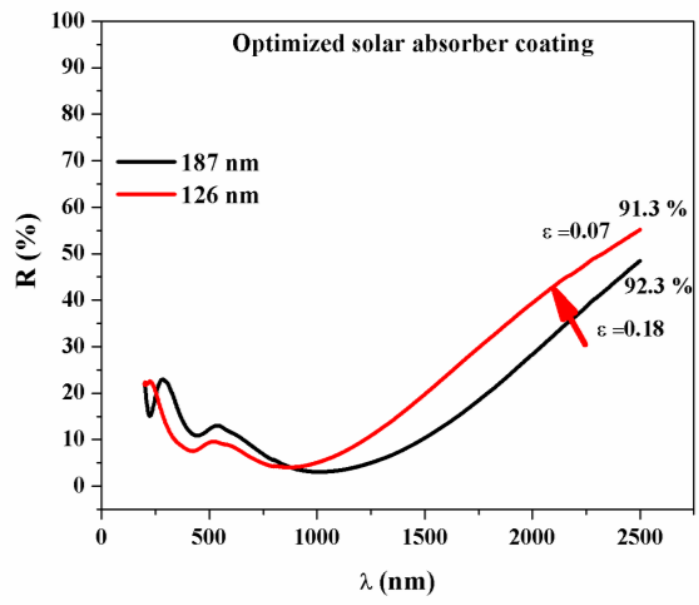

Figure 23: Reflectance spectra of optimized multilayer absorber. 
The overall elemental composition of individual optimized parameters of each layer were summarized in table 2.

Table 2: Elemental composition of individual layers in the optimized multilayer solar absorber coating.

\begin{tabular}{|c|c|c|c|c|c|c|c|c|}
\hline Sample & $\begin{array}{l}\mathrm{Ti} \\
\left(\text { Atanix } b_{0}\right)\end{array}$ & $\begin{array}{l}\mathrm{Cr} \text { (Atanix } \\
\text { bi) }\end{array}$ & 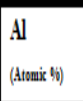 & \begin{tabular}{|l|}
$\mathrm{Si}$ \\
$\left(\right.$ Atani , $\left._{1}\right)$
\end{tabular} & \begin{tabular}{|l}
$\mathrm{N}$ \\
$($ Atani \\
(iv)
\end{tabular} & $\begin{array}{l}N_{p} \\
\text { (mbrr) }\end{array}$ & $\mathrm{I}_{\text {lager }}(\mathrm{m})$ & $\mathrm{n}$ \\
\hline AlSil & . & . & 27 & 9 & 67 & $2 \times 10^{2}$ & 35 & $\sim 1.95$ \\
\hline TillN & 12 & . & 34 & . & 54 & $2 \times 10^{2}$ & 30 & $\sim 1.77$ \\
\hline TiAlCrN+Ti & 14 & 10 & 19 & . & 57 & $5 \times 10^{3}$ & 61 & $\sim 1.84$ \\
\hline
\end{tabular}

\section{Structural and phase analysis from XRD}

Structure and phase analysis of each layer has been studied using GIXRD in the $2 \theta$ range $5-70^{\circ}$. Fig. 24,25 and 26 shows the XRD patterns of TiAlCrN, TiAlN and AlSiN layers respectively. TiAlCrN sample shows two strong crystalline peaks that corresponds to cubic- AlN (200) at $2 \theta$ angle $44.7^{\circ}$ and tetragonal $-\mathrm{Ti}_{2} \mathrm{~N}(220)$ at $2 \theta$ angle $52.2^{\circ}$. $\mathrm{Cr}_{2} \mathrm{~N}$ and $\mathrm{AlTi}_{3} \mathrm{~N}$ peaks are also observed and shown in figure 25. The deconvoluted spectra of individual peaks are shown in Fig. 25. Similarly, the XRD spectra of TiAlN show two major peaks: cubic- AlN (200) at $44.7^{\circ} 2 \theta$ and tetragonal- $\mathrm{Ti}_{2} \mathrm{~N}(220)$ at $52.2^{\circ}$ (Fig. 26). XRD-Spectra of AlSiN indicates presence of two phases, amorphous and hexagonal- $\mathrm{Si}_{3} \mathrm{~N}_{4}$ at $35.2^{\circ}, 52.1^{\circ}$ respectively and crystalline cubic- AlN (200) at $44.7^{\circ} 2 \theta$ (Fig. 27\&28). The AlSiN is found to form a nanocomposite structure with nano crystalline AlN surrounded by amorphous $\mathrm{Si}_{3} \mathrm{~N}_{4}$. It was evident by TEM analysis (Fig. 28).

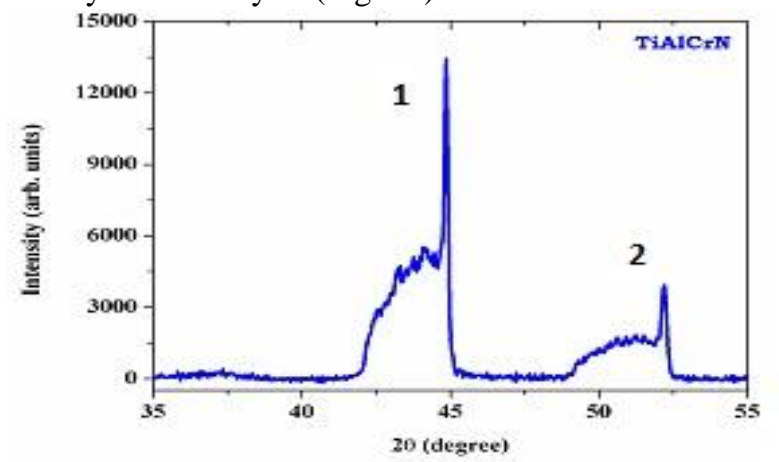

Figure 24: TiAlCrN - XRD.

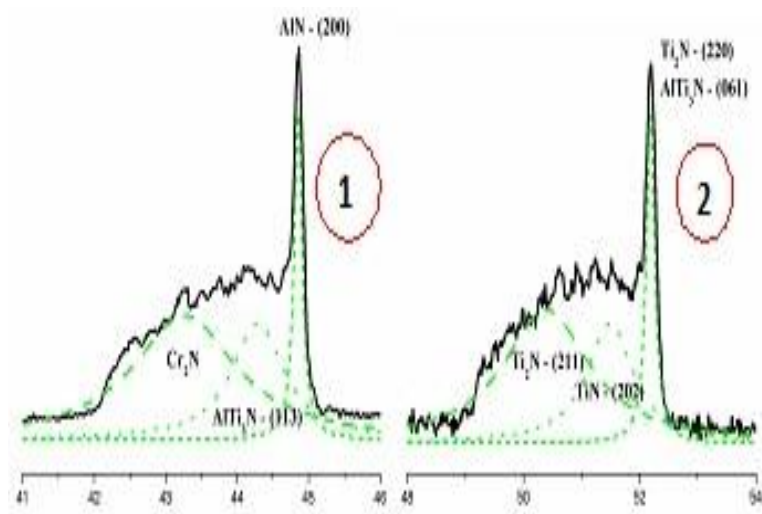

Figure 25: XRD spectra of two major peaks in TiAlCrN.

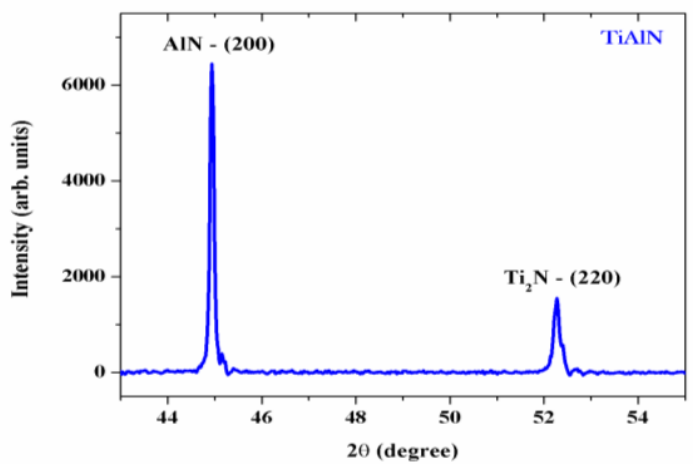

Figure 26 TiAIN XRD.

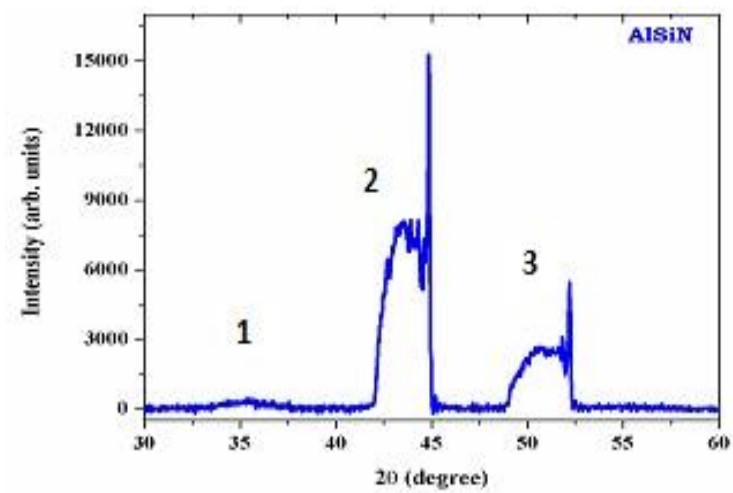

Figure 27: XRD- spectra of AISiN.

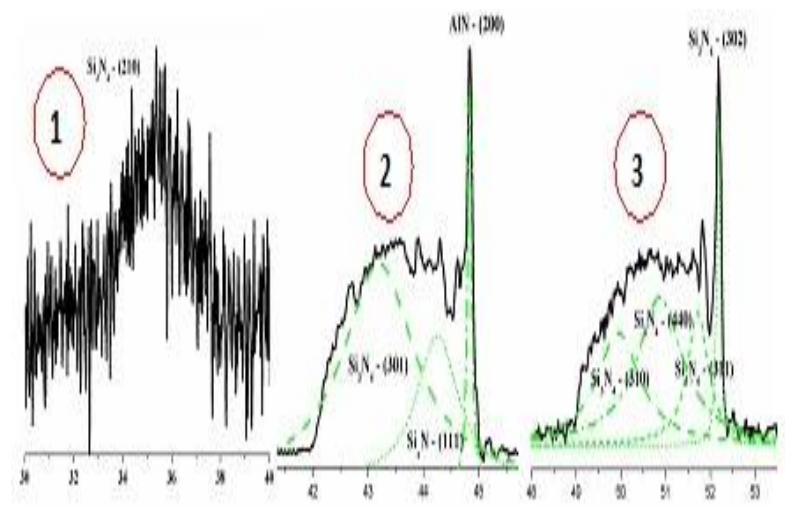

Figure 28: XRD - spectra of AlSiN indicating different peaks.

\section{Refractive index studies}

Ellipsometry has been used for the ' $n$ ' and ' $k$ ' measurement. Fig. 29 (a)-(c) shows the experimental $\Psi$ we have taken the values of spectra over a wavelength range 200-1000 $\mathrm{nm}$ for three different layers (multi layers) on Copper and SS - 316 substrate. The refractive index and extension coefficient values of the three multi layers (TiAlCrN, TiAlN and AlSiN) are clearly shown in the table.3 and comparison of experimental values and theoretical values are clearly in the graphical representation in the fig.29(a)-(c). The experimental values of the spectra has been compared with theoretical values of Lorentz model [21]. 
Table 3: Refractive index and extinction coefficient values of three layers of solar absorber coating.

\begin{tabular}{|llll|}
\hline S. No. & Layer & N & K \\
\hline $\mathbf{1}$ & TiAlCrN & 1.846 & 1.329 \\
\hline $\mathbf{2}$ & TiAlN & 1.773 & 1.605 \\
\hline $\mathbf{3}$ & AlSiN & 1.950 & 0.102 \\
\hline
\end{tabular}
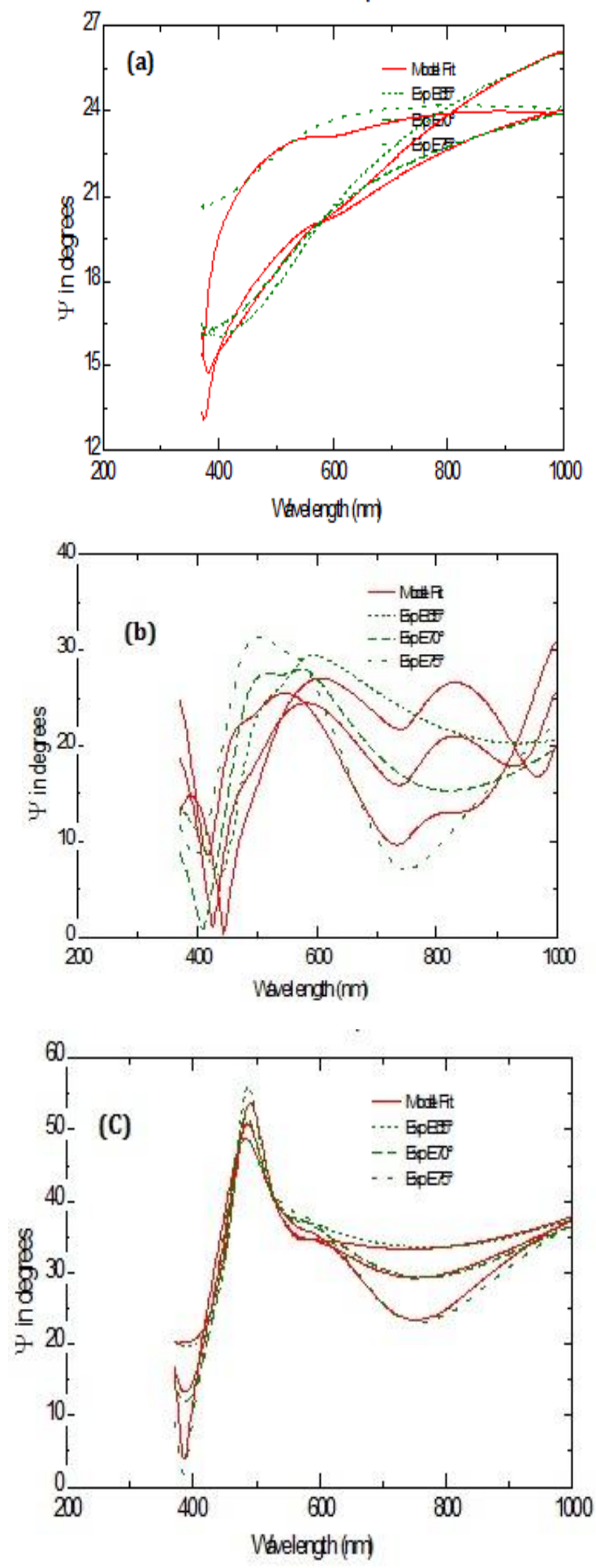

Figure 29: (a)-(c) Experimental determined and theoretical curve-fits, solid (red) line indicated theoretical curves and dotted (green) lines indicated experimental determined curves.

Thermal stability studies
In the thermal stability test (performed at open air condition), coatings were heated at a rate of $100^{\circ} \mathrm{C} /$ hour from room temperatures to $700^{\circ} \mathrm{C}$ and maintained there for 1 hour.

Table 4: Absorption and emission values of heat treated samples.

\begin{tabular}{|l|l|l|l|l|l|}
\hline S. No. & Temperature( $\left.{ }^{\circ} \mathrm{C}\right)$ & \multicolumn{2}{|l|}{ Before heat treatment } & \multicolumn{2}{l|}{ After heat treatment } \\
\hline & $\begin{array}{l}\text { Absoption } \\
(\%)\end{array}$ & Emission (\%) & $\begin{array}{l}\text { Absoption } \\
(\%)\end{array}$ & $\begin{array}{l}\text { Emission } \\
(\%)\end{array}$ \\
\hline 1. & 27 & 89.9 & 18 & - & - \\
\hline 2. & 400 & 89.0 & 18 & 89.0 & 18 \\
\hline 3. & 500 & 89.0 & 18 & 89.4 & 18 \\
\hline 4. & 600 & 89.0 & 18 & 91.7 & 20 \\
\hline 5. & 700 & 89.4 & 19 & 88.8 & 19 \\
\hline
\end{tabular}

Optical properties (i.e. absorption and emission) were measured before and after the heat treatment and found no much change up to $700^{\circ} \mathrm{C}$. The absorption and emission values before and after heat treatment were shown in Table 3.5. The plot of which could also be seen in Fig. 30. Barshilia et al. [5] developed TiAlN/TiAlON/ $/ \mathrm{Si}_{3} \mathrm{~N}_{4}$ multilayer absorber air stable up to $600^{\circ} \mathrm{C}$ only but these coatings were stable up to $700^{\circ} \mathrm{C}$.

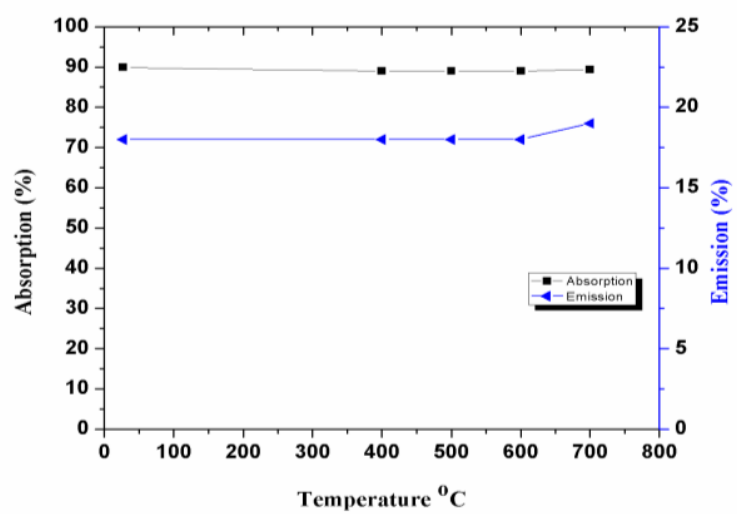

Figure 30: Temperature vs. emission and absorption values of multilayer coating.

\section{SUMMARY AND CONCLUSION}

Spectrally selective solar absorber coatings of TiAlCrN/TiAlN/AlSiN was deposited on $\mathrm{Cu}$, SS and $\mathrm{SiC}$ substrates using Cathodic arc physical vapour deposition (CAPVD) technique. Each layer in the multilayer stack has been optimized by varying the different influencing deposition parameters. The major identified parameters are reactive $\mathrm{N}_{2}$ partial pressure, Cathode powers (metal content and thickness) and substrate bias and deposition temperatures. The thickness of each layer was optimized such that, there occurs a destructive interference of reflected light enhancing absorption. With the detailed optimization and understanding of the deposition parameters and multilayer structure, the best optical properties were achieved: $\alpha=0.91, \varepsilon=0.07$ for TiAlCrN/TiAlN/AlSiN coating. The TiAlCrN/TiAlN/AlSiN coating has high

Published By: 
thermal stability up to $700^{\circ} \mathrm{C}$ temperature in ambient condition. This high temperature stability is attributed to the high temperature stability of TiAlN and observed Nanocomposite structure formation in the AlSiN layer. The crystalline n-AlN and amorphous a-Si ${ }_{3} \mathrm{~N}_{4}$ Nano-composite structure formation was confirmed using TEM analysis. The refractive index and extinction coefficients of each layer were estimated by Ellipsometry using well known Lorentz model. The experimental spectra were nearly fitted with theoretical model. The coatings has good adherence with a delaminating force of $21.5 \mathrm{~N}$. The formation of DLC was understood from Raman studies which show a sharp peaks at 1353 and $1577 \mathrm{~cm}^{-1}$.

\section{REFERENCES}

1. C. G. Granqvist, Solar energy materials, Appl. Phys. A 52 (1991) 83-93.

2. Electric Power Research Institute, 1997, Renewable Energy Technology Characterizations, Tropical Report No. 109496, Palo Alto CA

3. C. E. Kennedy, Review of Mid- to High-Temperature Solar Selective absorber Materials, NREL/TP-52031267, July 2002.

4. Jyoti Lata Pandey and M. K. Banerjee, Anti-Corrosion Methods and Materials Vol.45 No.1 (1998) 16-24.

5. Devinder Kumar Kaushal, An overview of Solar Thermal Devices, Renewable Energy, Vol 10 (1997), 355-361.

6. Y. Yin, Y. Pan, L. X. Hang, D. R. Mckenzie, M. M. M. Bilek, Thin Solid Films 517 (2009) 1601-1606.

7. V. Godinho, D. Philippon, T. C. Rojas, N. N. Novikova, V.A. Yakovlev, E. A. Vinogradov, A. Fernandez, Solar Energy 84 (2010) 1397-1401.

8. Harish C. Barshilia, n.Selvakumar andK.S.Rajam, J. Appl. Phys. 103 (2008) 023507.

9. Qui-Chu Zhang, Sol. Energy Mater. Sol. Cells 62 (2000) 63-74.

10. G. B. Smith, A. Ben-David, P.D. Swift, Renewable Energy 22 (2001) 79-84.

11. M.G. Hutchins, Sufrace Technology, 20 (1983) 301-320.

12. A. Antonaia, A. Castaldo, M. L. Addonizio, S.Esposito, Sol. Energy Mater. Sol. Cells 94 (2010) 1604-1611.

13. M. Farooq, M. G. Hutchins, Sol. Energy Mater. Sol. Cells 71 (2002)73-83.

14. Shuxi Zhao, Ewa Wackelgard, Sol. Energy Mater. Sol Cells 90(2006) 243-261.

15. Harish C. Barshilia, n.Selvakumar andK.S.Rajam, J. Appl. Phys. 103 (2008) 023507.

16. Y. Yin and R. E. Colling, J.Appl. Phys. 77 (1995) 12.

17. Kiyoshi Chiba and Shota Kaminishi, Jpn. J. Appl. Phys., 47 (2008) 1.

18. Qui Zhang, J. Vac. Sci. Technol. A Vol. 15(1997) 6.

19. 19. Miao Du, Lei Hao, Jing Mi, Fang Lv, Xiaopeng Liu, Lijun Jiang, Shumao Wang, Sol. Energy Mater. Sol. Cells 95 (2011)1193-1196.

20. Harish C. Bharshilia, Prashant kumar, K. S. Rajam, A. Biswas, , Sol. Energy Mater. Sol. Cells (2011), doi: 10.1016/j.solmat.2011.01.034.

21. Harish C. Barshilia, N. Selvakuma, and K.S. Rajam, D.V. Sridhara Rao, K.muraleedharan and A. Biswas, Appl. Phys. Lett. 89 (2006) 191909.

22. J. J. Cuomo, J. F. Ziegler, and J. M. Woodall, A new concept for solar energy thermal conversion, IBMResearch, Yorktown Heights, New York 10598

23. G.B. Smitha, A. Ben-David, P.D. Swift, A new type of TiN coating combining broad band visible transparency and solar control, Renewable Energy 22 (2001) 79 \pm 84

24. Dawei Ding, Weimin Cai, a novel design for hightemperature solar selective coating
25. Carl m.Lampert, advanced optical materials for energy efficiency and solar conversion, Solar \& Wmd Technology Vol 4, No3, pp 347-379, 1987

26. Y. Yin, D.R. McKenzie, W.D. McFall, Cathodic arc deposition of solar thermal selective surfaces, Solar Energy Materials and Solar Cells 44 (1996) 69-78

27. H. Randhawa, Thin Solid Films 167 (1988) 175 